\title{
DOSES DE NITROGÊNIO NO CRESCIMENTO DE PORTA-ENXERTO DE GOIABEIRA PALUMA AMARELA
}

\author{
Doses ses of nitrogen on the growth of rootstock goiabeira paluma yellow
}

\author{
Sônia Costa França ${ }^{1}$, Alessandra Conceição de Oliveira ${ }^{2}$, Geyci Aires Fariass ${ }^{3}$, Lucíula Ferreira Cabral Junior ${ }^{3}$, Valéria \\ Lima da Silva ${ }^{3}$ \\ ${ }^{1}$ Graduanda, Engenharia Agronômica, Universidade do Estado de Mato Grosso - UNEMAT; sonia_nx@hotmail.com \\ 2Dra. Professora departamento de Agronomia, Universidade do Estado de Mato Grosso - UNEMAT; acoliviera@hotmail.com \\ ${ }^{3}$ Graduadas, Engenharia Agronômica, Universidade do Estado de Mato Grosso - UNEMAT; valeria.silva21@hotmail.com
}

Artigo enviado em 21/03/2017, aceito em 13/05/2017 e publicado em 07/07/2017.

RESUMO: O presente trabalho teve como objetivo avaliar os efeitos de doses de nitrogênio no crescimento de porta-enxertos de goiabeira amarela. O experimento foi conduzido na Universidade do Estado de Mato Grosso (UNEMAT), campus de Nova Xavantina, no período de 12 de setembro a 02 de dezembro de 2015, utilizando o delineamento experimental em blocos ao acaso, para a análise de produção, com 5 tratamentos $(0 ; 150 ; 300 ; 450$ e $600 \mathrm{mg} \cdot \mathrm{dm}^{-3}$ de N), e para análise de crescimento utilizou-se fatorial duplo, sendo nove analises de crescimento (44, 51, 58, 65, 72, 79, 86, 93 e 100 dias após a semeadura) e 5 doses de nitrogênio, e quatro repetições e dez plantas por parcela. A fertirrigação procedeu-se de uma solução de água mais doses de nitrogênio, variando de acordo com cada tratamento. Sendo avaliadas as características para a análise de crescimento: altura da parte aérea, número de folhas, diâmetro do colo, e para a análise de produção altura da parte aérea, número de folhas, diâmetro do colo, comprimento do sistema radicular, massa verde e seca das folhas, caule e raízes foi avaliada aos 100 DAS. Conclui-se que as doses de 300 e $450 \mathrm{mg} \cdot \mathrm{dm}^{-3}$ foram mais efetivas no crescimento de porta-enxertos de goiabeira amarela, indicando que as mudas estavam aptas para serem transplantadas no campo aos 72 e 79 DAS, e aos 100 DAS foram observados os maiores valores para todas as características avaliadas na dosagem de $300 \mathrm{mg} \cdot \mathrm{dm}^{-3}$.

Palavras-chave: fertirrigação, produção de mudas, Psidium guajava L., ureia

\begin{abstract}
The fertigation plays an important role in fruit seedlings production phase, it ensures proper development and precocity in production. Therefore the aim of this study was to evaluate the effects of nitrogen on the growth of rootstocks yellow guava. The experiment was conducted at the State University of Mato Grosso (UNEMAT), campus of Nova Xavantina, from September 12 to December 2, 2015, using the experimental design of randomized blocks with five treatments and four replications and ten plants per plot. The treatments consisted of doses $0 ; 150 ; 300 ; 450$ and 600 mg.dm-3 N. The fertigation proceeded in a water solution over nitrogen, varying according to each treatment. They were evaluated at 42, 49, 56, 63, 70,79, 86, 93 and 100 days after sowing (DAS) growth characteristics: shoot height, leaf number, stem diameter, length of the root system, already fresh and dry weight of leaves, stems and roots was evaluated at 100 DAS. It is concluded that the doses of 300 and 450 mg.dm-3 were more effective in the growth of rootstocks yellow guava, indicating that plants were ready to be transplanted in the field at 80 DAS and the DAS 100 were observed the higher values for all traits.
\end{abstract}

Keywords - fertigation, seedling production, Psidium guajava L., urea

\section{INTRODUÇÃO}

O Brasil é um dos maiores produtores mundiais de frutas, possuindo características privilegiadas de solo e clima para o desenvolvimento da fruticultura tropical e subtropical (SEBRAE, 2015).

A produção de mudas de qualidade é um desafio, pois vários fatores, entre os quais qualidade da semente, tipo de recipiente, substrato, adubação e manejo influenciam nesse processo (OLIVEIRA et al., 2015).

A prática da adubação mineral com macro e micronutrientes resultam em ganhos de produtividade das culturas implantadas em diversos solos brasileiros, 
uma vez que estes possuem, de forma geral, baixos teores dos elementos indispensáveis ao crescimento vegetal. Dessa forma, pesquisas vêm buscando informações sobre as fontes, concentrações e sobre a melhor forma de aplicação dos nutrientes (SILVA et al, 2001).

Com nutrição adequada, mudas e plantas em produção ficam menos suscetíveis ao ataque de pragas e doenças, toleram melhor períodos de seca e outros estresses, além de elevar a produtividade, qualidade dos frutos e início de produção precoce (DIAS, et al. 2012). Assim é imprescindível a aplicação de fertilizantes minerais durante os estádios iniciais de crescimento e desenvolvimento da planta quando jovem, podendo está apresentar redução do crescimento por qualquer deficiência nutricional, de modo que as aplicações subsequentes não têm o mesmo efeito que o verificado em plantas adubadas apropriadamente desde o início de sua formação (SOUZA et al., 2001).

O nitrogênio e o potássio são os dois nutrientes mais requeridos pela goiabeira (FRANCO et al., 2007) e possuem papel fundamental nos estádios iniciais de crescimento das mudas, devendo seu parcelamento considerar a exigência das plantas, a cinética de absorção dos elementos e a dinâmica dos nutrientes no substrato. Em geral, a quantidade de nutrientes presentes nos substratos é suficiente apenas o primeiro estádio de crescimento das mudas, havendo necessidade de adubação para a planta completar seu ciclo de desenvolvimento no viveiro (DIAS et al., 2012).

No cenário agrícola mundial de frutas, a goiaba é pouco comercializada. $\mathrm{Na}$ União Européia e nos Estados Unidos, considerados os maiores mercados consumidores de produtos hortifrutícolas do mundo, a fruta é considerada exótica, sendo comercializada em escala mínima e a preços elevados (SILVA-JÚNIOR,2009).

Embora o Brasil seja o maior produtor mundial de goiaba, sua participação no mercado internacional da fruta "in natura" é inexpressiva, mostrando que há necessidade de pesquisas com essa frutífera que é apreciada por todos brasileiros (ROZANE, et al, 2007).
Uma das principais considerações há serem feitas, quanto a análise da cultura da goiabeira, refere-se à carência de dados oficiais sistematizados sobre a produção mundial de goiaba, onde existem poucos estudos sobre o cultivo e o manejo de adubação de mudas da cultura.

Diante do exposto, objetivou-se, com este trabalho, avaliar o desenvolvimento de mudas no crescimento de porta-enxerto de goiabeira paluma amarela com diferentes doses de nitrogênio.

\section{MATERIAL E MÉTODOS}

O experimento foi conduzido no período de 12 de setembro a 02 de dezembro de 2015, no viveiro com tela de sombreamento de $50 \%$ de luminosidade situado na área experimental da UNEMAT, Câmpus de Nova Xavantina-MT, localizado nas coordenadas $14^{\circ} 41^{\prime} 09^{\prime \prime} \mathrm{S}$ e $52^{\circ} 20^{\prime} 09^{\prime}$ W e altitude média de $275 \mathrm{~m}$. O clima é Aw de acordo com a classificação de Köppen, com temperatura média anual de $20^{\circ} \mathrm{C}$, com duas estações bem definidas, uma seca (abril a setembro) e uma chuvosa (outubro a março) com precipitação pluviométrica média anual de $1.600 \mathrm{~mm}$ (NIMER, 1989). Durante a execução do experimento foi registrada uma temperatura média máxima de $44^{\circ} \mathrm{C}$ e temperatura média mínima de $23^{\circ} \mathrm{C}$, com umidade do ar média de $62 \%$ e precipitação de $129 \mathrm{~mm}$. As condições climáticas mencionadas foram favoráveis ao desenvolvimento de mudas de goiabeira.

As mudas utilizadas nesta pesquisa foram obtidas de sementes da empresa Arbocenter, sendo utilizada a cultivar Paluma Amarela, com $97 \%$ de germinação e $99 \%$ de pureza, conforme dados do fabricante. As sementes foram semeadas em saquinhos de polietileno com as dimensões de 14 x $20 \mathrm{~cm}$, com capacidade para um litro $\left(\mathrm{dm}^{3}\right)$ de substrato, que foi composto por solo e esterco bovino na proporção (3:1), e as características químicas do substrato estão apresentadas na Tabela 1. Foram coloca três sementes em cada saquinho e após a estabilização da germinação, que ocorreu aos 30 dias após a semeadura foi feito o desbaste deixando-se apenas a mais vigorosa. A emergência iniciou 15 dias após a semeadura. 
Tabela 1. Resultados da análise química e física do substrato utilizado no experimento de mudas de goiabeira. Nova Xavantina, MT.

\begin{tabular}{|c|c|c|c|c|c|c|c|c|c|c|c|c|c|}
\hline $\mathrm{pH}$ & $\mathrm{Ca}$ & $\mathrm{Mg}$ & $\mathrm{Al}$ & $\mathrm{H}+\mathrm{Al}$ & SB & $\mathrm{K}$ & $\mathrm{P}$ & \multirow{2}{*}{$\begin{array}{l}\text { CTC } \\
\mathrm{cmol}_{\mathrm{c}} \\
\mathrm{dm}^{-3}\end{array}$} & $\mathrm{~V}$ & M.O. & Argila & Silte & Areia \\
\hline & \multicolumn{5}{|c|}{---1---- $\mathrm{cmol}_{\mathrm{c}} \mathrm{dm}^{-3}$} & \multicolumn{2}{|c|}{$-\mathrm{mg} \mathrm{dm}^{-3}-$} & & $\%$ & & $--\mathrm{g} / \mathrm{k}_{\xi}$ & & \\
\hline 7,8 & 3,21 & 2,0 & 0,12 & 2,20 & 12,6 & 7,35 & 13,9 & 12,6 & 85,1 & 33,70 & 192,0 & 50 & 758,0 \\
\hline
\end{tabular}

Foi utilizado o delineamento experimental em blocos ao acaso, com cinco tratamentos sendo:(T1:0 (testemunha); T2:150; T3:300; T4:450 e T5:600 mg.dm3 de $\mathrm{N}$ ), e para análise de crescimento utilizou-se fatorial duplo, sendo nove analises de crescimento (44, $51,58,65,72,79,86,93$ e 100 dias após a semeadura) e 5 doses de nitrogênio, e quatro repetições e dez plantas por parcela (Figura 1). Hernandes et al. (1996), na qual avaliaram a resposta da figueira à aplicação de doses de nitrogênio, 0, 150, 300, 450, 600, $750 \mathrm{~g}_{\text {planta }}{ }^{-1}$, e verificaram que a máxima produção $(14,2 \mathrm{t} / \mathrm{ha})$ foi obtida com a dose de $379 \mathrm{~g} \mathrm{planta}^{-1}$ de $\mathrm{N}$.
A fertirrigação constituiu-se de solução de água na qual adicionou-se doses de ureia $(\mathrm{N})$, variando de acordo com cada tratamento. Agitou-se manualmente a solução de maneira a dissolver o fertilizante (ureia) e em seguida aplicou-se a solução em cada saquinho, com auxílio de uma seringa com o volume de $20 \mathrm{ml}$ sobre o substrato. As aplicações do fertilizante foram realizadas aos 51, 65 e 79 dias após a semeadura (DAS).

Para as avaliações utilizou-se apenas oito plantas centrais, sendo as outras duas consideradas como bordadura conforme representado na Figura 1.

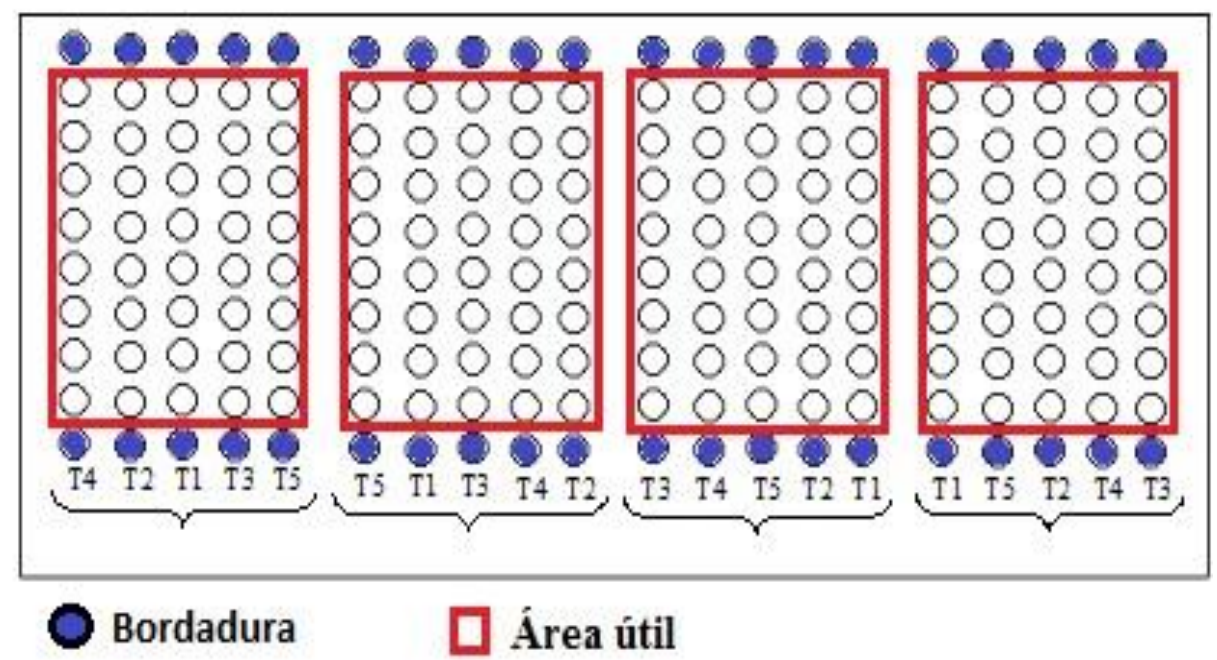

Figura1. Representação esquemática da distribuição dos tratamentos dentro do viveiro. Nova Xavantina, MT.

Os tratos culturais utilizados foram: a irrigação feita com regador, controle de pragas foi realizado de forma mecânica e as plantas daninhas foram controladas manualmente.

Aos 44, 51, 58, 65, 72, 79, 86, 93 e 100 DAS foram mensuradas as características de crescimento: altura da parte aérea, número de folhas, diâmetro do colo. E no final do experimento, aos 100 DAS, analisou altura da parte aérea, número de folhas, diâmetro do colo, radicular comprimento do sistema radicular, massa verde e seca das folhas, caule e raízes.
Aos atingiram 44 dias após a semeadura foi realizada a primeira medição dos parâmetros de crescimento como: determinação da altura da portaenxerto, medindo-se a distância entre o colo e o ápice da porta-enxerto, utilizando uma régua graduada em milímetro; número de folha por planta, contagem de folhas desenvolvidas maiores que $1 \mathrm{~cm}$; e diâmetro do colo realizando a medição da porta-enxerto na região do colo, com o auxílio de um paquímetro digital.

Aos 100 dias após a semeadura, as mudas foram coletadas e imediatamente levadas ao Laboratório de Solos Retirou-se a muda do substrato 
cuidadosamente e o sistema radicular foi lavado em água corrente para retirar o excesso de terra com os devidos cuidados para que o mesmo não fosse danificado. As plantas foram separadas em parte aérea, sistema radicular com o auxílio de um canivete, em seguida foram mensurados o comprimento das raízes e altura da parte aérea.

O comprimento do sistema radicular foi medido do colo ao extremo da raiz e a altura da parte aérea foi medida do colo ao ápice, ambos foram medidos separadamente com o auxílio de uma régua graduada, obtendo valores em centímetros.

Para obtenção da massa verde, pesou-se separadamente folhas, caules e raízes das plantas de cada parcela em uma balança analítica para obter valores totais expressos em gramas. Para determinação da massa seca, as mudas foram colocadas em saquinhos de papel, etiquetadas e levadas à estufa com circulação forçada de ar a temperatura de $65^{\circ}$ por $72 \mathrm{~h}$, para assim atingirem massa constante. Logo após esse período foi feita a pesagem do material e obteve-se a peso seca total somando-se a massa seca da parte aérea (folhas e caule) e sistema radicular.

Os resultados foram submetidos à análise de variância e as médias foram submetidas à análise de regressão para as doses de nitrogênio e para dias após semeadura (DAS), ao nível de 5\% de probabilidade. As análises foram realizadas pelo programa computacional Sistema para Análise de Variância - SISVAR (FERREIRA, 2000).

\section{RESULTADOS E DISCUSSÃO}

Com base na Tabela 2, observa-se que houve diferença significativa para número de folhas (NF), altura da parte aérea (APA) e diâmetro do caule (DIA) tanto para doses quanto para dias após a semeadura quando avaliados isoladamente. Quando se analisa a interação entre doses e dias após a semeadura houve significância apenas para altura da parte aérea.

Tabela 2. Resumo da análise de variância para número de folha (NF), altura da parte aérea (APA), diâmetro do Colo (DIA) submetidas a diferentes doses de nitrogênio. Nova Xavantina, MT.

\begin{tabular}{lllll}
\hline \multirow{2}{*}{ FV } & \multirow{2}{*}{ G.L. } & \multicolumn{3}{c}{ Quadrado Médio } \\
\cline { 3 - 5 } & & NF & APA & DIA \\
\hline Doses & 4 & $85,29^{* *}$ & $354,01^{* *}$ & $2,16^{* *}$ \\
DAS & 8 & $308,52^{* *}$ & $1524,03^{* *}$ & $15,83^{* *}$ \\
Doses*DAS & 32 & $8,77^{\mathrm{ns}}$ & $39,73^{*}$ & $0,291^{\mathrm{ns}}$ \\
\hline Bloco & 3 & $109,55^{* *}$ & $458,11^{* *}$ & $8,68^{* *}$ \\
Resíduo & 132 & 9,05 & 26,06 & 0,28 \\
\hline CV & -- & 22,32 & 26,44 & 20,31 \\
\cline { 3 - 5 } significativo a 1\%. * significativo a 5\%. ns não significativo a 1\% e 5\%. Doses e DAS = análise de regressão.
\end{tabular}

Com as curvas de crescimento das mudas de goiabeira (Figuras 2, 3 e 4 ) pode-se estimar o tempo necessário para as mudas estarem aptas ao plantio em campo.

$\mathrm{Na}$ Figura 2, observa-se que apesar não ter sido significante a probabilidade de $1 \%$ e $5 \%$, a dosagens $300 \mathrm{mg} \cdot \mathrm{dm}^{-3}$ teve destaque quando comprada a testemunha que não apresentou um aumento significativo no número de folhas. O número de folhas depende da formação e desenvolvimento de primórdios foliares, enquanto que a área foliar unitária é função da expansão celular (TÁVORA et al., 2001), assim, os resultados sugerem que a formação e o desenvolvimento das folhas foram sensíveis a escassez e ao excesso de nitrogênio na planta. 


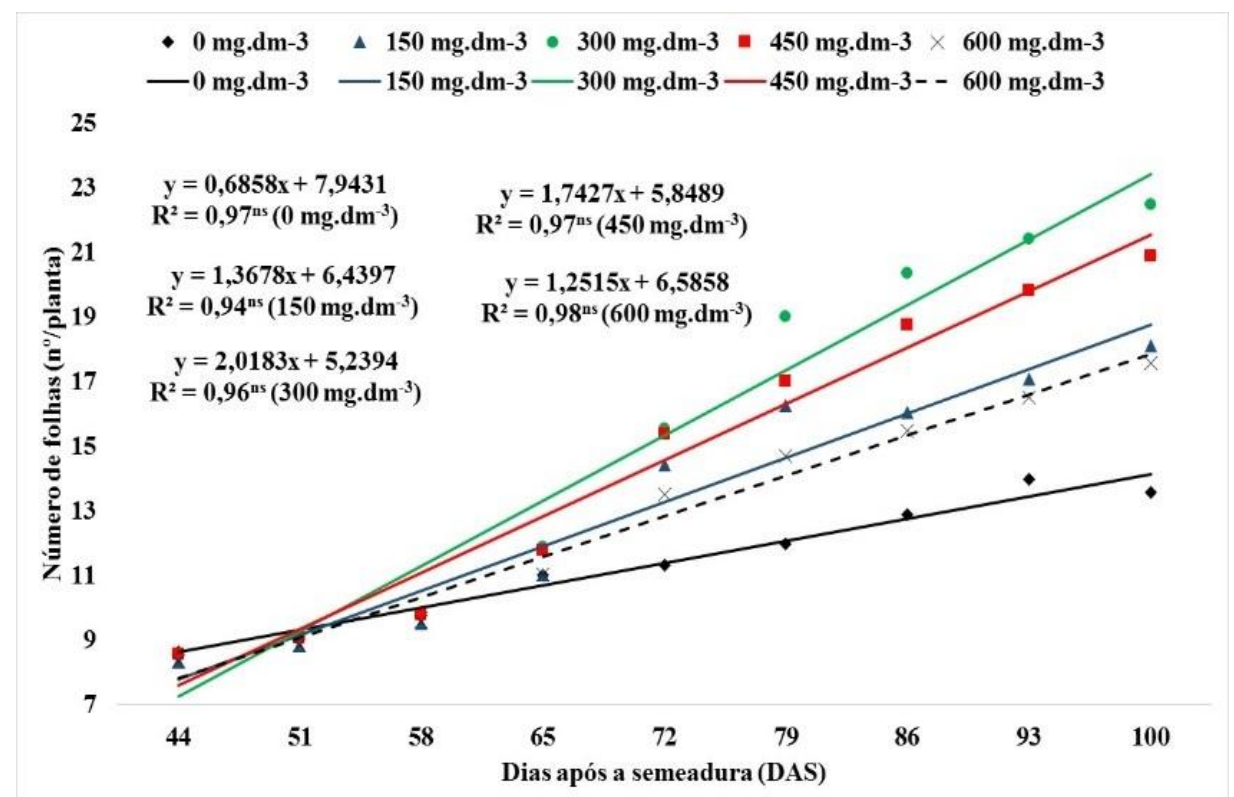

Figura 2. Número de folhas de porta-enxerto de goiabeira paluma amarela em função de doses de nitrogênio. Nova Xavantina, MT.

Ao analisar a Figura 3, as mudas de goiabeira atingiram a altura entre 15 a $25 \mathrm{~cm}$ para todos os tratamentos: para a testemunha aos 79 DAS com valor de $16,75 \mathrm{~cm}$, para a dosagem de $300 \mathrm{mg} \cdot \mathrm{dm}^{-3}$ aos 72 DAS com o valor de 20,73, na dosagem de 450 mg.dm ${ }^{-}$ 3 o valor de $20,05 \mathrm{~cm}$ aos 65 DAS. Em relação ao diâmetro do colo apenas as dosagens 450 e 600 mg.dm 3 atingiram valor padrão recomendado de portaenxerto, aos 93 dias 4,27 $\mathrm{mm}$ e aos 100 dias com 4,22 $\mathrm{mm}$, respectivamente (Figura 3).

Observa-se de na Figura 3, que houve diferença estatística entre os tratamentos para a altura das portaenxerto, e a dosagem de $450 \mathrm{mg} \cdot \mathrm{dm}^{-3}$ foi superior aos demais tratamentos, chegando ao porte recomendado por Sturion (2000), aos 72 DAS (dias após semeadura), onde as mudas estavam aptas a irem a campo com acima de 15 a $25 \mathrm{~cm}$. Para todos os tratamentos tiveram a altura mínima recomenda ao final do experimento, aos 100 DAS.

Segundo Carneiro (1995), porta-enxerto com maior diâmetro de colo apresentaram melhor equilíbrio do crescimento da parte aérea, não recomendando o plantio de porta-enxerto com diâmetro de colo inferior a 3,7 mm. (CHAVES et al. 2000) afirmam que os porta-enxertos de goiabeira devem ter haste única e ereta com um mínimo de oito folhas verdadeiras maduras, altura entre 15 e $25 \mathrm{~cm}$, diâmetro de 4,0 a 5,0 $\mathrm{mm}$ (Figura 3). 


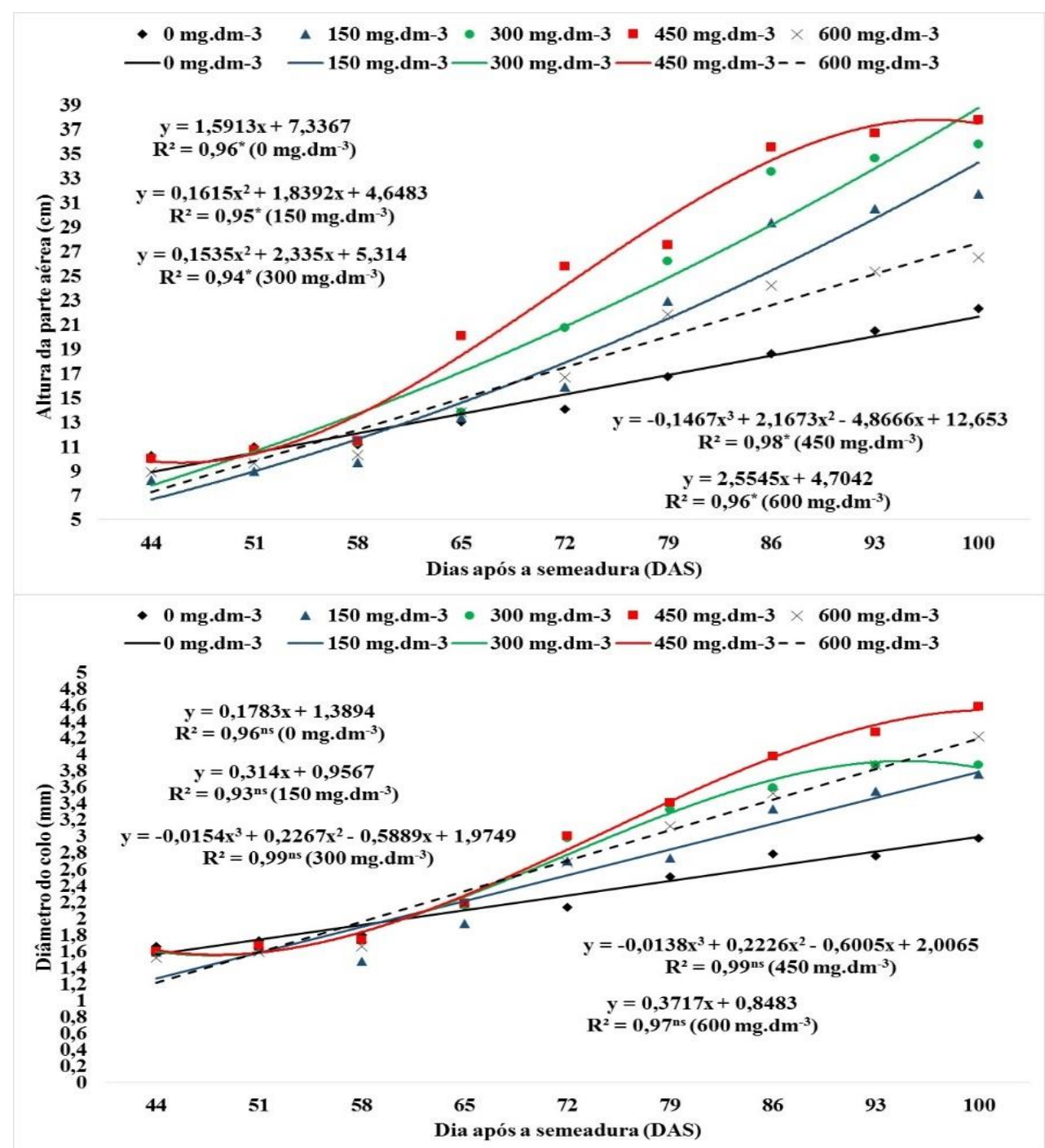

Figura 3. Altura da parte aérea e diâmetro do colo de porta-enxerto de goiabeira paluma amarela em função de doses de nitrogênio. Nova Xavantina, MT.

Ao analisar a figura 4, observa-se maiores valores da relação altura/diâmetro na maior dose de $\mathrm{N}$ utilizada. Se o valor da altura/diâmetro do colo for elevado, pode indicar que, na parte aérea, a partição da massa seca privilegia o crescimento longitudinal, se não houver, como contrapartida, um aumento do diâmetro do colo proporcional ao crescimento em altura, pode ocorrer o tombamento da muda. Por outro lado, valor muito baixo da relação altura e diâmetro do colo, apesar de representar menor risco de tombamento, pode indica que o crescimento em altura é lento, comprometendo a competição no campo, com plantas infestantes. De acordo com carneiro (1995), esta relação altura/diâmetro do colo deve situar-se de forma intermediária, sendo que em casos de grande variação, torna-se preferível os menores valores, escolhendo mudas mais resistentes (STURION; ANTUNES, 2000). 


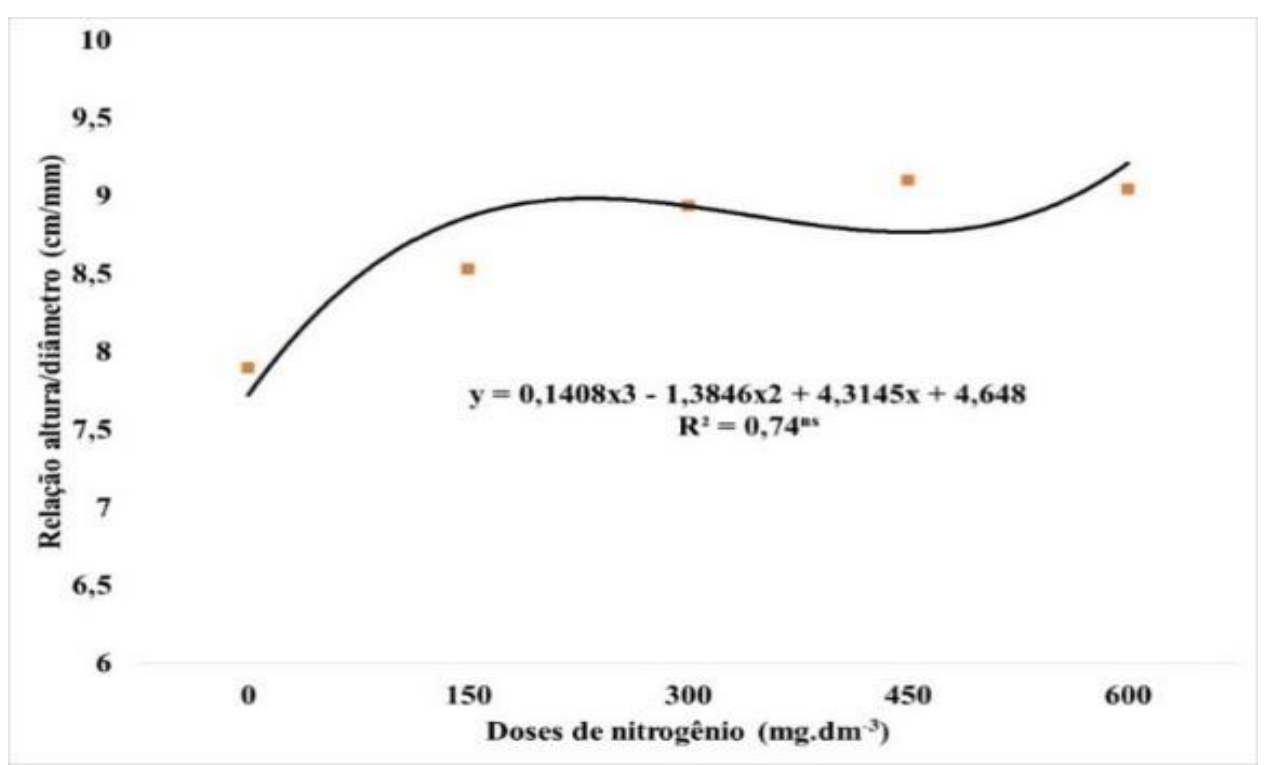

Figura 4. Relação altura/diâmetro $(\mathrm{cm} / \mathrm{mm})$ de porta-enxerto de goiabeira paluma amarela em função das diferentes doses de nitrogênio. Nova Xavantina, MT.

Analisando a Tabela 3, não houve diferença significativa entre os tratamentos pelo teste $\mathrm{F}(\mathrm{P}<0,01$ e 0,05$)$ para a maioria dos parâmetros, exceto para altura da parte aérea das mudas (APA).

A falta de nitrogênio e/ou excesso causaram reduções na altura das plantas, número de folhas, e diâmetro do colo (figuras 5, 6 e 7), embora não tenha ocorrido diferença estatística entre os tratamentos para essas duas últimas características. O número de folhas teve uma redução por planta de $40 \%$ e $22 \%$ para a testemunha e dose de $600 \mathrm{mg} \mathrm{dm}^{-3}$, respectivamente, quando comparada a dosagem de $300 \mathrm{mg} \cdot \mathrm{dm}^{-3}$.

A altura da planta apresentou redução de $41 \%$ e $26 \%$, para a testemunha e dose de $600 \mathrm{mg} \mathrm{dm}^{-3}$, respectivamente, quando comparada a dosagem de 300 mg. $\mathrm{dm}^{-3}$. De acordo com silva et.al. (2015), isto pode ter ocorrido devido a um desequilíbrio nutricional causando pelo excesso de n, ou uma desordem fisiológica pelo excesso de aplicações de doses crescentes de ureia.

Para carneiro (1995), a altura das mudas, juntamente com o diâmetro do colo, constitui num dos mais importantes parâmetros morfológicos para estimar o crescimento das mudas após o plantio definitivo em campo. De acordo com (KNAPIK 2005), o diâmetro do colo é tido como a característica morfológica que melhor se ajusta aos modelos de predição de sobrevivência das mudas em campo. O diâmetro tem um papel fundamental, pois reflete no acúmulo de reservas nutritivas, favorece o bom desenvolvimento do sistema radicular e pode assegurar que a muda apresenta maior resistência e melhor fixação ao solo (ELOY et al., 2014). 
Tabela 3. Resumo da análise de variância par Número de folha (NF), altura da parte aérea (APA), diâmetro do dolo (DIA) e relação altura da parte aérea/diâmetro do solo $(H / D)$ submetidas a diferentes doses de nitrogênio. Nova Xavantina, MT.

\begin{tabular}{|c|c|c|c|c|c|c|}
\hline \multirow{2}{*}{ F.V. } & \multirow{2}{*}{ G.L. } & \multicolumn{5}{|c|}{ Quadrado médio } \\
\hline & & $\mathrm{NF}$ & APA & DIA & $H / D$ & $\mathrm{CR}$ \\
\hline Tratamento & 4 & $46,80^{\mathrm{ns}}$ & $164,42^{*}$ & $1,83^{\text {ns }}$ & $1,77^{\mathrm{ns}}$ & $7,55^{\text {ns }}$ \\
\hline Bloco & 3 & $36,42^{\text {ns }}$ & $144,48^{\text {ns }}$ & $2,05^{\text {ns }}$ & $9,76^{\text {ns }}$ & $8,36^{\mathrm{ns}}$ \\
\hline Resíduo & 12 & 23,49 & 51,34 & 0,61 & 4,24 & 3,59 \\
\hline $\mathrm{CV}$ & -- & 26,17 & 23,25 & 21,51 & 23,66 & 10,61 \\
\hline \multirow{2}{*}{ F.V. } & \multirow{2}{*}{ G.L. } & \multicolumn{5}{|c|}{ Quadrado médio } \\
\hline & & MVR & MVF & & MVC & MVT \\
\hline Tratamento & 4 & $1,38^{\mathrm{ns}}$ & $7,06^{\mathrm{ns}}$ & & $22,15^{\text {ns }}$ & $58,06^{\mathrm{ns}}$ \\
\hline Bloco & 3 & $3,27^{\mathrm{ns}}$ & $4,91^{\text {ns }}$ & & $23,15^{\mathrm{ns}}$ & $59,79^{\mathrm{ns}}$ \\
\hline Resíduo & 12 & 0,86 & 5,03 & & 14,47 & 33,88 \\
\hline $\mathrm{CV}$ & -- & 32,54 & 43,52 & & 32,64 & 29,60 \\
\hline \multirow{2}{*}{ F.V. } & \multirow{2}{*}{ G.L. } & \multicolumn{5}{|c|}{ Quadrado médio } \\
\hline & & MSR & MSF & & MSC & MST \\
\hline Tratamento & 4 & $0,32^{\mathrm{ns}}$ & $1,41^{\mathrm{ns}}$ & & $0,22^{\mathrm{ns}}$ & $4,44^{\mathrm{ns}}$ \\
\hline Bloco & 3 & $0,31^{\mathrm{ns}}$ & $0,69^{\mathrm{ns}}$ & & $0,57^{\mathrm{ns}}$ & $4,15^{\mathrm{ns}}$ \\
\hline Resíduo & 12 & 0,18 & 0,82 & & 0,35 & 2,31 \\
\hline $\mathrm{CV}$ & -- & 20,34 & 27,04 & & 24,40 & 19,28 \\
\hline
\end{tabular}

A testemunha $\left(0 \mathrm{mg} \mathrm{dm}^{-3}\right.$ de $\left.\mathrm{N}\right)$ apresentou maior comprimento do sistema radicular, esse resultado possivelmente ocorreu devido à ausência de adubação o que pode ter promovido na planta um alongamento do sistema radicular como tentativa de buscar o nutriente em profundidade (Figura 5). Outros trabalhos como (GOMES; PAIVA; 2004), com diferentes espécies têm apresentado o efeito prejudicial de altas doses nitrogenadas sobre o sistema radicular, o comprimento do sistema radicular constitui um dos parâmetros usados para avaliar a qualidade de mudas, esta característica geralmente reflete no acúmulo de reservas nutritivas.

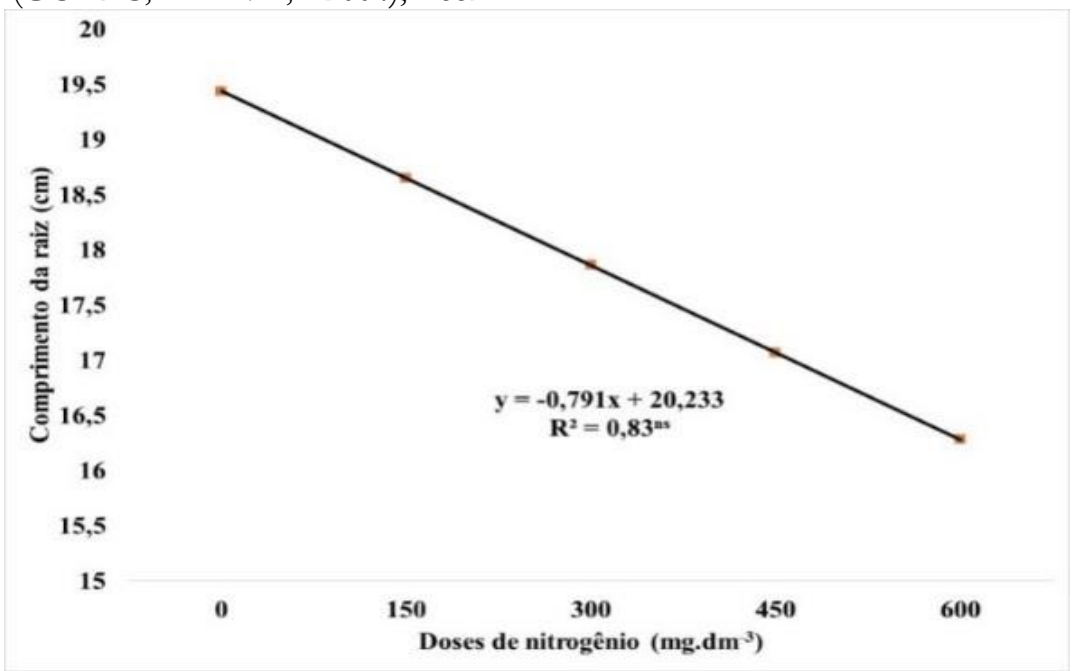

Figura 5. Comprimento da raiz $(\mathrm{mm})$ de porta-enxerto de goiabeira paluma amarela em função das diferentes doses de nitrogênio. Nova Xavantina, MT. 
Para Eloy et al. (2014), o peso de massa seca da raiz é muito utilizado para avaliar a qualidade de mudas indicando rusticidade e correlacionando-se diretamente com a sobrevivência e o desempenho inicial das mudas após o plantio no campo. Verifica-se com a na Figura 6, que a falta ou excesso de nutrientes causa o desbalanço nutricional da planta o que explica a regressão nos gráficos de massa verde e massa seca do sistema radicular das mudas de goiabeira e apresentando o melhor desenvolvimento nas doses 265 e $343 \mathrm{mg} \cdot \mathrm{dm}^{-3}$.

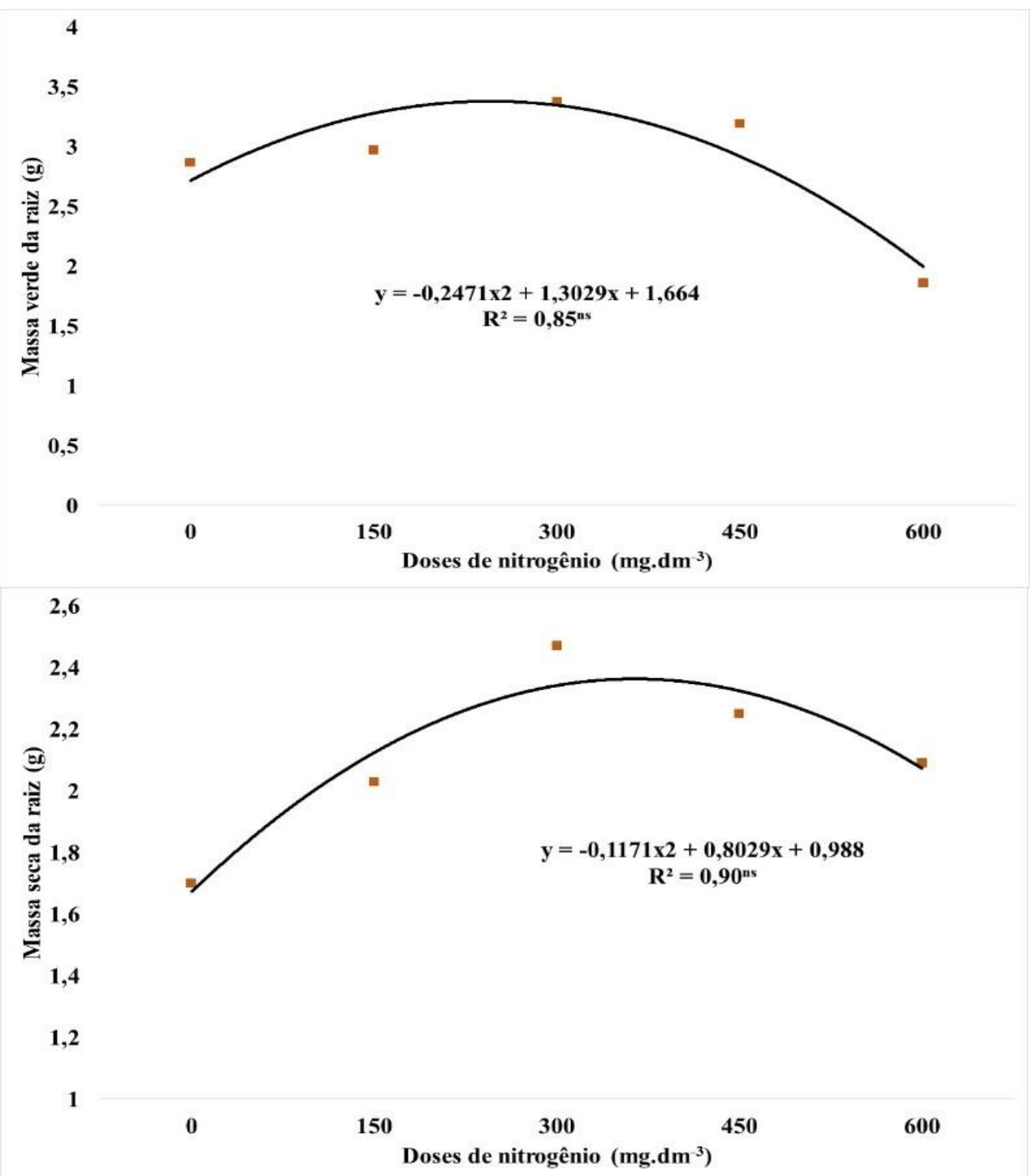

Figura 6. Massa verde e seca da raiz (g) de porta-enxerto de goiabeira paluma amarela em função das diferentes doses de nitrogênio. Nova Xavantina, MT.

Estudos com doses de $\mathrm{N}$ na forma de nitrato de amônio $\left(\mathrm{NH}_{4} \mathrm{NO}_{3}\right)$ no cultivo de maracujazeiro em solução nutritiva observaram que altas doses reduziram o peso da massa seca da raiz, o mesmo autor descreve que possivelmente a diminuição no crescimento não foi devido ao desbalanço de $\mathrm{N}$ com um ou mais nutrientes, ou a toxicidade do nitrato (no3), mas pode ter sido devido a toxicidade do $\mathrm{NH}^{+4}$ (CARLOS NETO et al., (1994). 
Apesar de não significativos, as doses de nitrogênio influenciaram no acúmulo de massa verde e seca total (Figura 7). Observa-se que houve ajuste quadrático para ambos, onde as menores e maiores doses proporcionaram o menor acúmulo de massa, e as doses 300 e $325 \mathrm{mg} \cdot \mathrm{dm}^{-3}$ resultaram em maiores acúmulos, sendo os valores 24,97 g e $21,47 \mathrm{~g}$, respectivamente. Segundo Minami (2010), o produtor precisa de uma muda com base e estrutura bem definida, porém não só tamanho da muda é importante, mas também os aspectos de massa seca que têm que ser uniforme na muda, assim considerando raiz, parte aérea, diâmetro do caule, número de folhas e tamanho da raiz. Ciriello (2014), afirmam que as plantas, de modo geral, respondem bem à adubação nitrogenada, sendo que o efeito externo do nitrogênio mais visível é a vegetação verde e abundante, porém o excesso de $\mathrm{N}$ é prejudicial, sendo que a dose fornecida à cultura deve ser equilibrada.

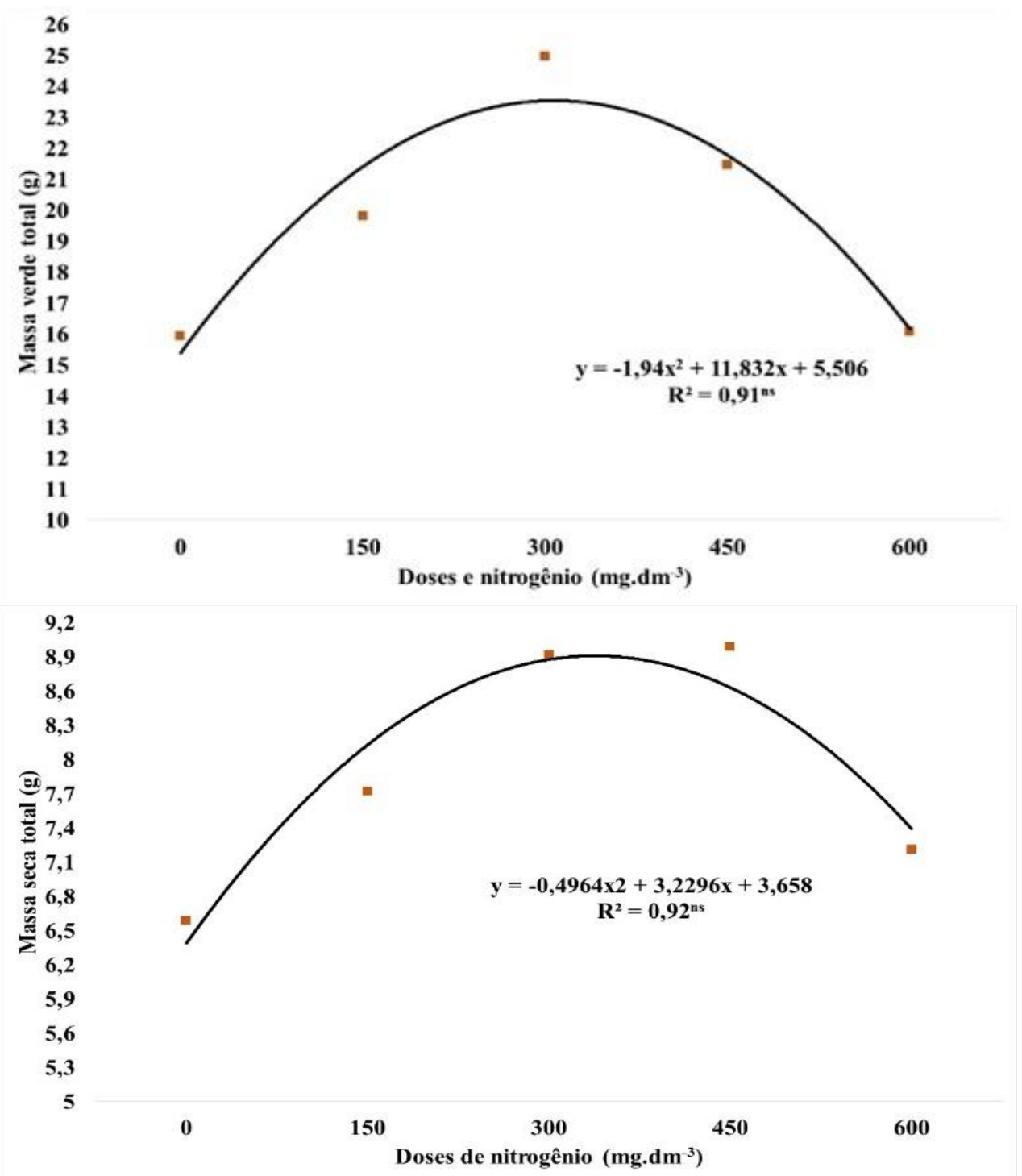

Figura 7. Massa verde e seca total (g) de porta-enxerto de goiabeira paluma amarela em função das diferentes doses de nitrogênio. Nova Xavantina, MT. 


\section{CONCLUSÃO}

Conclui-se que as doses de 300 e 450 mg. $\mathrm{dm}^{-3}$ foram mais efetivas no crescimento de porta-enxertos de goiabeira amarela variedade paluma, indicando que as mudas estavam aptas para serem transplantadas no campo aos 72 e 79 DAS, e aos 100 DAS foram observados os maiores valores para todas as características avaliadas na dosagem de $300 \mathrm{mg} \cdot \mathrm{dm}^{-3}$.

\section{REFERÊNCIA BIBLIOGRÁFICA}

CARLOS NETO, A. de; GRANDI, A. J. de; VICHIATO, M.; AMARAL, A. M. do.; SOUZA, M. de. Viabilização do uso de tubetes para obter o portaenxerto de citros limoeiro cravo com "solução de arranque". In: CONGRESSO BRASILEIRO DE FRUTICULTURA, 13, Salvador, 1994. Resumos... Salvador: Sociedade Brasileira de Fruticultura, v.3, p.400-401. 1994.

CARNEIRO, J. G. A. Produção e controle de qualidade de mudas florestais. Curitiba: UFPR/FUPEF; Campos: UENF, 451p. 1995.

DIAS, M. J. T.; SOUZA, H. A.; NATALE, W.; MODESTO, V. C.; ROZANE, D. E. Adubação com nitrogênio e potássio em mudas de goiabeira em viveiro comercial. Semina: Ciencias Agrárias, Londrina, v.33, p. 2837-2848. 2012.

FERREIRA, D. F. Manual do Sistema Sisvar para análises estatísticas. Lavras: Departamento de ciências exatas, 2000.

FRANCO, F. C.; PRADO, R. M.; BRACHIROLLI, L.F.; ROZANE, D. E. Curva de crescimento e marcha de absorção de macronutrientes em mudas de goiabeira. Revista Brasileira de Ciência do Solo, Viçosa, v. 31, n. 6, p.1429-1437, 2007.

GOMES, J. M., PAIVA, H. N. Viveiros florestais: propagação sexuada. 2. Ed. Viçosa: UFV. 116 p. 2004.
KNAPIK, G. J. Utilização do pó de basalto como alternativa à adubação convencional na produção de mudas de Mimosa scabrella Benth e Prunussellowii Koehne. 2005. 163p. Dissertação (Mestrado em Engenharia Florestal) - Universidade Federal do Paraná, Curitiba, 2005...

MINAMI, K. Produção de Mudas de Alta Qualidade. Piracicaba, SP: ESALQ, 2010. 101-130p.

NIMER, E. Climatologia do Brasil. Rio de Janeiro: IBGE, 422 p. 1989.

OLIVEIRA, F. T.; HAFLE, O. M.; MENDONÇA, V.; MOREIRA, N.; PEREIRA, E. B.J.; ROLIM, H. O. Respostas de porta-enxertos de goiabeira sob diferentes fonte e proporções de materiais orgânicos. Paraíba/PB: ComunicataScientiae.v.6, n.1. p. 17-25. 2015.

SILVA-JÚNIOR, A. A. Otimização da desidratação osmótica da goiaba (Psidium guajava L.).2009. 102p. Dissertação apresentada ao curso de pós-graduação em engenharia química do Centro de tecnologia e geociências do departamento de engenharia química da Universidade Federal de Pernambuco, para título de Mestre em Engenharia Química, Recife- PB,2009.

SILVA, E. M.; NOBRE, R. G.; SOUZA, L. P.; ABRANTES, D. S.; ANDRADE, A. B. A. Efeito da adubação nitrogenada na formação de mudas de goiabeira irrigadas com águas salinizadas. Revista Verde: Pombal - PB, vol. 10, nº 4, p. 42 - 48, 2015.

STURIOn, J. A. ANTUnes, B. M. A. Produção de mudas de espécie florestais. In: GALVÃO, A. P. M. Reflorestamento de propriedades rurais para fins produtivos e ambientais. Colombo: PR, p.125-150, 2000. 
HERNANDEZ, F.B.T.; SUZUKI, M. A.; FRIZZONE, J. A.; TARSITANO, M. A. A.; PEREIRA, G.T.; CORRÊA, L. S. Função de resposta da figueira (Ficus carica L.) à aplicação de doses de nitrogênio e lâminas de água. Revista Engenharia Agrícola, v.16, n.2 p.22-30, 1996.

TÁVORA, F. J. A. F.; FERREIRA, R. G.; HERNANDEZ, F. F. F. Crescimento e relações hídricas em plantas de goiabeira submetidas a estresse salino com NaCl. Rev. Bras. de Fruticultura, vol. 23. n.2, p. 441-446. 2001.

ELOY, E.; CARON, B. O.; TREVISAN, R.; BEHLING, A.; SCHMIDT, D.; SOUZA, V. Q. Determinação do período de permanência de mudas de Eucalyptus grandis W. Hill ex Maiden em casa de vegetação.Com. Sci., Bom Jesus, v.5, n.1, p.44-50, 2014.

CARneiro, J. G. A. Produção e controle de qualidade de mudas florestais. Curitiba: UFPR/FUPEF; Campos: UENF, 451p. 1995.

STURION, J. A. ANTUNES, B. M. A. Produção de mudas de espécies florestais. In: GALVÃO, A. P. M.
Reflorestamento de propriedades rurais para fins produtivos e ambientais. Colombo: PR, p.125-150, 2000.

SEBRAE. Agronegócio: Fruticultura. Out. /2015.

SILVA, R. P.; PEIXOTO, J. R.; JUNQUEIRA, N.T. V. Influência de diversos substratos no desenvolvimento de mudas de maracujazeiro azedo (Passiflora edulis Sims f. flavicarpa Deg). Revista Brasileira de Fruticultura, Jaboticabal, v. 23, n. 2, p. 15, 2001.

SOUZA, V.F. de.; COELHO, E.F. Manejo de fertirrigação em fruteiras. In: FOLEGATTI, M.V. (Coord.). Fertirrigação: flores, frutas e hortaliças. Guaíba: Agropecuária, v.2, cap.2, p.71-103. 2001.

OLIVEIRA, F. T.; HAFLEL, O. M.; MENDONÇA, V.; MORIRAL, J. N.; PEREIRA JÚNIOR, E. B.; MARACAJA, P. B. Produção de mudas de goiabeira com diferentes fontes e proporções de adubos orgânicos. Revista Verde. v 9., n. 2, p. 111 - 116, 2014. 